\title{
An Investigation of Clear Air Stratification With Radar and Elevated Instruments ${ }^{1}$
}

\author{
D. R. Hay and K. Naito ${ }^{2}$ \\ Department of Physics, University of Western Ontario, London, Canada
}

(Received November 16, 1964)

\begin{abstract}
A study of radar reflections within the clear air of the lower troposphere has been carried out over two prolonged intervals. A specially designed radar operating at $7000 \mathrm{MHz}$ has been used for this purpose, with its stationary antennas directed vertically into the layer of frictional influence. An interpretation of these radar observations has been made with the aid of synoptic weather information, to indicate that the incidence of reflections varies with the type of air mass and with the degree of dampness of the underlying ground. The distribution of reflecting centers generally has a maximum at a height of $300 \mathrm{~m}$, but this distribution is altered by the intrusion of a weather front. These reflecting centers appear to be small departures in air refractivity within horizontal layers that are only a few centimeters in vertical depth and that are either flat or weakly concave downwards, extending over horizontal distances of at least a few meters. The need for further information on the air structure to support these radar observations has led to a program of special instrument development. Included are a balloon-borne refractometer and temperature sonde which have a rapid response and a high degree of spatial resolution, and a smoke-generating nose cone for low level rockets. Preliminary observations have been carried out with these instruments to assess their capabilities, and some details on the smoke trail analysis are given in this paper. Inspection of the smoke trails indicates localized layers of turbulence and rapid diffusion within deeper layers of laminar translation. It appears that averaging times in excess of $20 \mathrm{~min}$ are required to obtain some mean wind-speed profiles. The vertical extent of velocity inhomogeneities is not small as compared with their horizontal extent, and the law of diffusion generally is different at levels above and below $300 \mathrm{~m}$.
\end{abstract}

\section{Introduction}

Information on the fluctuations of air refractivity in the troposphere is important to many aspects of radio propagation. By some means which is not clear, these inhomogeneities reflect, refract, and scatter radio waves passing through the troposphere. It is well known that common refractivity fluctuations are associated with inhomogeneities in the air temperature and humidity, but few details on their physical dimensions and their relationship to the environment are available at the present time, especially for heights more than a few meters above ground. Direct evidence of microstructure in air refractivity has been obtained from many observations with the microwave refractometer; these are limited, however, to relatively brief periods of time and to a small volume of space. An alternative procedure is to examine a designated volume of the troposphere with a sensitive radar. Radar reflections from a sensibly clear region of the air are called radar angels, and the interpretation of these reflections will lead to a better understanding of the microstructure of air temperature and humidity.

\footnotetext{
${ }^{1}$ Presented in part at the 1964 World Conference on Radio Meteorology, Boulder, Colo., 1 Presented in part at the 1964 World Conference on Radio Meteorology, Boulder, Colo.,
14-18 September. The research reported in this paper was supported by the Defence 14-18 September. The research reported in this paper was supported by the Defence
Research Board of Canada under Grant 2801-12, and by the Research and Development Research Board of Canada under Grant 2801-12, and by the Research and Development
Laboratories of the Northern Electric Company, Ottawa, through DDP Contract Serial No. 9PC1-436.

${ }^{2}$ On leave of absence from the Meteorological Research Institute, Tokyo.
}

Information on microwave radar angels has been obtained over two prolonged intervals. This study has made use of a specially designed radar of high sensitivity, operating at a frequency at $7000 \mathrm{MHz}$; the separate transmitting and receiving antennas are stationary and directed vertically with their beams overlapping at ranges greater than $150 \mathrm{~m}$ above ground. Attention here is confined to levels below $1500 \mathrm{~m}$, in the layer of frictional influence. Further details on this work are reported elsewhere [Hay and Reid, 1962; Bell, Hay, and Johnston, 1964].

The interpretation of this radar study has suggested a scale of microstructure in the lower troposphere that cannot be detected by conventional airborne instruments. The reflecting centers are as shallow as a few centimeters in the vertical, through which the change in refractivity is of the order of $1 \mathrm{ppm}$, and the horizontal extent is at least a few meters. These lamina are either flat or weakly concave downwards, and their lifetimes may vary from a small fraction of 1 sec to many tens of minutes. Their incidence is governed by the type of air mass in which they are located, and by the dampness of the underlying ground. In general, their maximum occurrence is at a height of $300 \mathrm{~m}$ above ground. This single maximum is resolved into two maxima by the intrusion of a frontal zone. Periodicity in the angel incidence also suggests a possible modification of the microstructure by internal gravity waves. 
It is clear at this stage that auxiliary soundings of the lower troposphere are desirable to complement the radar observations. Although this work has indicated that microwave angels may be produced by the refractivity contrasts at air parcels that are transferred and eroded in turbulent eddies, or at the lower boundary of a subsiding air mass, or at the advection layers above adjacent columns of air over regions of ground with different albedo, yet an entirely different mechanism also has been postulated. Plank [1956] has drawn attention to the similarities and differences between radar angels and the habits of insects and birds in the troposphere; some workers claim that all radar angels are attributed to swarming insects or birds in flight. At the present time, it is not possible to support either side of this controversial interpretation with adequate experimental evidence. Further advances in this type of research will require direct measurement of the fine structure of the air in the region observed by the radar.

\section{Instrumentation for Direct Probing of the Troposphere}

A program of instrument development to aid in the angel study is underway at the University of Western Ontario. These instruments are designed to observe the air temperature, refractivity, and wind shear in the lower troposphere with a high degree of spatial resolution. The temperature sonde and the refractometer are light-weight devices that are borne aloft by a standard radiosonde balloon. Prototypes of these have been raised through $200 \mathrm{ft}$ to confirm the existence of small fluctuations in temperature and refractivity within height intervals of only a few inches [Turner and Hay, 1963]. Further development is continuing, through a study of refractometer response at high relative humidities [Hay and Turner, 1963], and through the combination of the refractometer and temperature sonde into a single unit that also will permit computation of the humidity fluctuations.

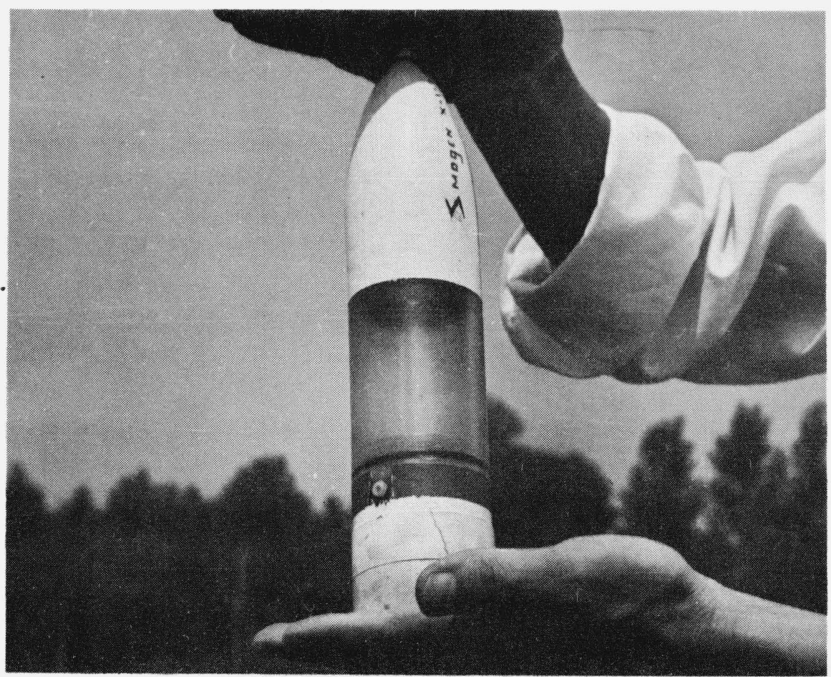

FIGURE 1. The smoke-generating nose cone for the Cricket rocket.
A study of wind shear in the lower troposphere also has been initiated. For this purpose, an instantaneous smoke trail is deposited in the vertical by a rocketborne smoke generator, and subsequent deformations of this trail are recorded photographically. This technique has been described by Gill, Bierly, and Kerawalla [1963]. The smoke-generating nose cone that was developed by the authors differs in some respects with that described by Gill et al. Figure 1 shows a photograph of this nose cone; the clear section contains $135 \mathrm{ml}$ of titanium tetrachloride, for ejection under a pressure of 60 psi through two $1 / 32$ in. nozzles to produce a smoke trail some $2500 \mathrm{ft}$ in length. The white upper section of the nose cone is pressurized with carbon dioxide gas to drive a free piston. The latter has a double seal with teflon "O"-rings, separating the gas from the titanium tetrachloride. Two techniques are used to retain the fluid in different models of the nose cone prior to launching; in one, blow-out plugs are inserted over the jets and are held in place by the wall of the launching tube; in the second, an inertial valve closes the channel leading to the jets until it is opened by the initial rocket acceleration.

\section{Preliminary Analysis of the Wind-Shear Profile}

Five sequences of smoke-trail deformation have been observed during the late summer. Figure 2 shows a sample of the photographic recording; in this series, the trail position was observed at 3 -sec intervals. Inspection shows several interesting features of the air motion: these include the general horizontal translation of the trail, the slow diffusion of some sections, the rapid diffusion and deformation of other sections, and the generally rapid dispersion of the trail within $100 \mathrm{~m}$ of the ground.

The aim of these preliminary observations is to ascertain the potential of smoke trail analysis in studying tropospheric microstructure. Three investigations of vertical rocket trails have been reported elsewhere [Tolefson and Henry, 1961; Cooke, 1962; Gill, Bierly, and Kerawalla, 1963], but these have dealt only with the mean translation of the trail. In the present work, the first analytical step requires transcription of the trail images from the separate photographs to a single chart. Figure 3 shows two examples of these transcriptions; the sequence on the left illustrates not only the irregular translation of the trail but also the localized regions of rapid diffusion. Abrupt changes in the gradient of horizontal wind speed are apparent in the sequence on the right.

One conclusion that has been derived from this study concerns the averaging time for mean wind profiles. Two trail sequences have been observed at the same location, but differing in time by $20 \mathrm{~min}$. From these, the profile of average horizontal velocity of translation has been deduced for each trail, as illustrated in figure 4 . The notable differences between the two profiles indicate that an averaging time of 20 min is not sufficient to give a mean wind velocity profile in this example. A more complete study of averaging time is necessary. 

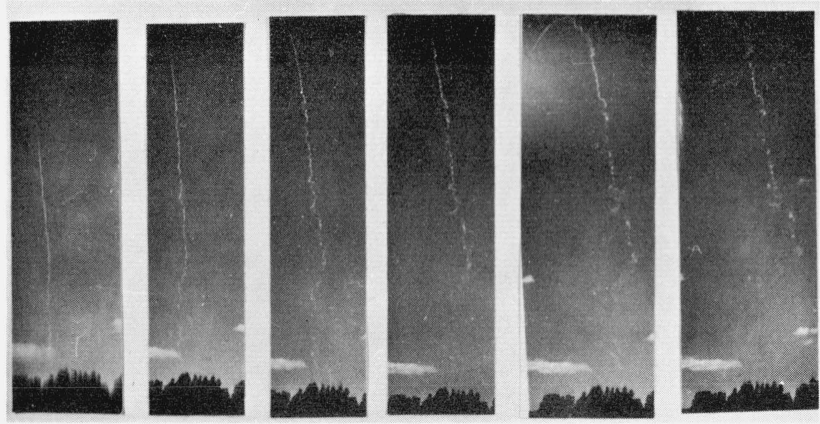

Figure 2. Photographic sequence of the deformation and diffusion of a smoke trail.
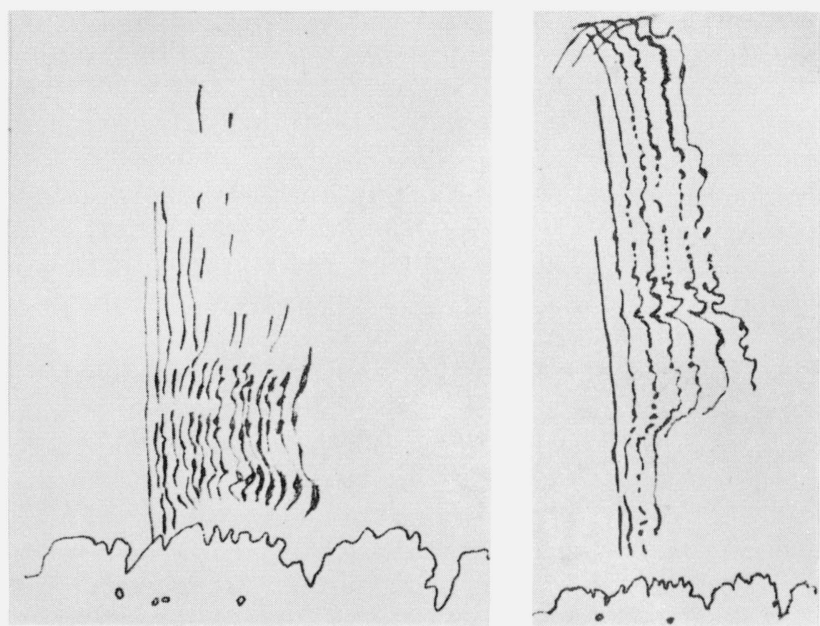

FIGURE 3. Two sample transcriptions of the sequential positions of separate smoke trails.

A second conclusion is related to the rate of smoke diffusion at various heights above ground. Although the preliminary observations described above have suggested a much greater rate of diffusion near the ground than at higher levels, the trail density near the ground was not sufficient for a quantitative analysis. For this reason, reference is made to observations upon smoke puffs in Nebraska as reported elsewhere by Lettau and Davidson [1957]. Figure 5 shows representative profiles of smoke duration, as derived from information on the Nebraska trails. Several charts of this type have been prepared for different synoptic weather conditions, and all show the same general features: a change in the rate of diffusion occurs at a height between 200 and $400 \mathrm{~m}$ above ground. Below this level, the duration of the smoke puff increases monotonically with height on a logarithmic scale, while the diffusion rate changes more slowly with height above this level. The UWO observations also have indicated considerable variability in the trail diffusion at levels above the transition height.

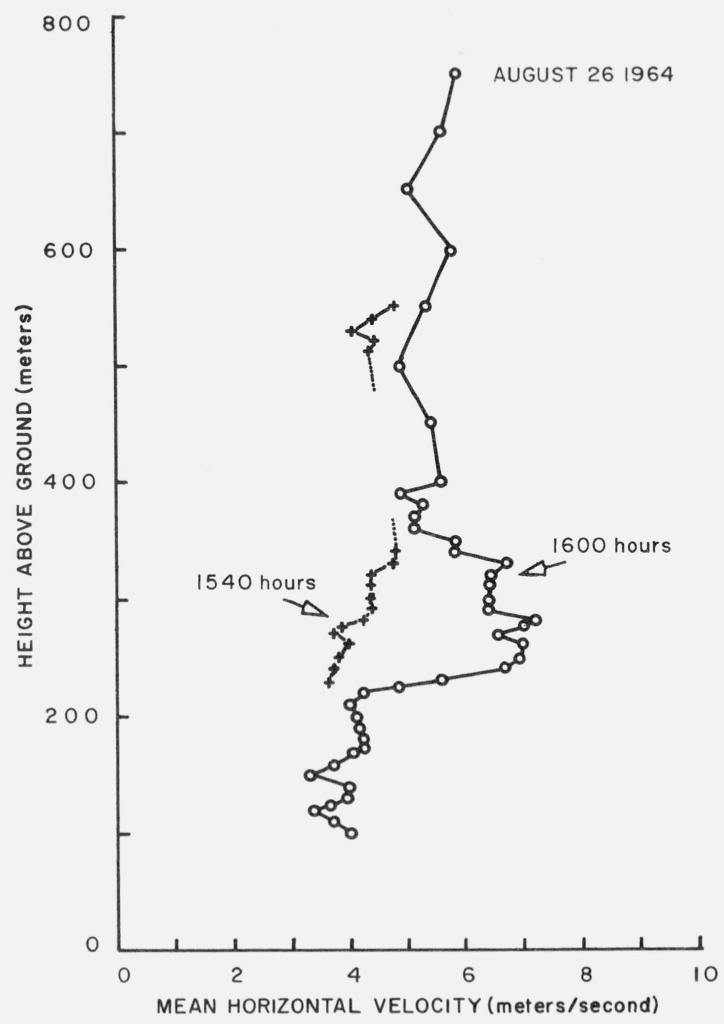

FIGURE 4. Vertical profiles of mean wind velocity for two rocket smoke trails at the same location but separated in time by $20 \mathrm{~min}$.

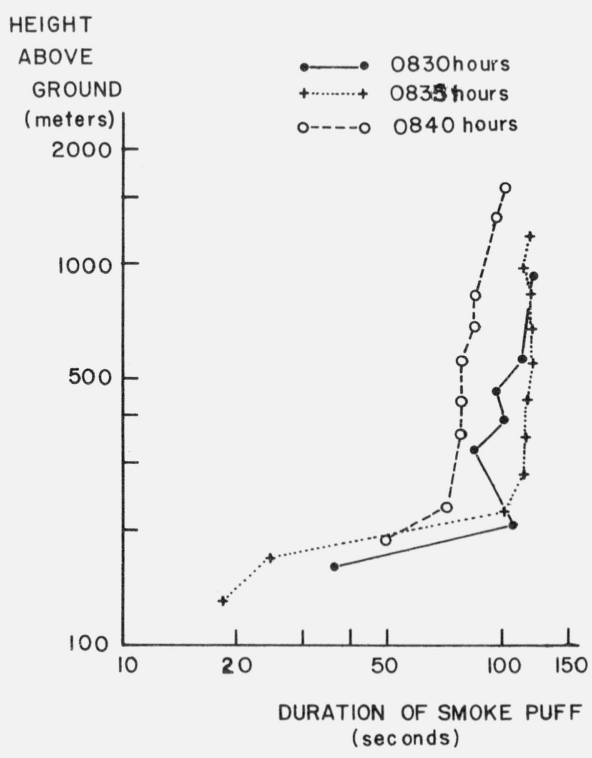

FigURE 5. Duration of smoke puffs as observed at O'Neill, Nebraska, as a function of height above ground, deduced from information provided by Lettau and Davidson [1957]. 
The deformation of a smoke trail provides a convenient source of information on the turbulent structure of the air. If the time-sequence of smoke trail photographs is observed at precise intervals, differences between the instantaneous velocity (in the drift plane) and the average translational velocity may be deduced as in a Lagrangian reference frame. Since the timing was not sufficiently precise for this purpose in the UWO trail photographs, information reported elsewhere by Cooke [1962] has been examined for microstructure in velocity. Figure 6 illustrates the analysis of velocity structure, as deduced from Cooke's trail profiles. Here, the lines represent contours of constant velocity departure from the mean; all contour intervals are equal, between maxima $(+)$ and minima $(-)$. The heavy solid lines coincide with the mean velocity. It is clear from this diagram that the scale of iso-anomalies in velocity is different at these heights than at the ground, where the horizontal dimension generally is much greater than the vertical.

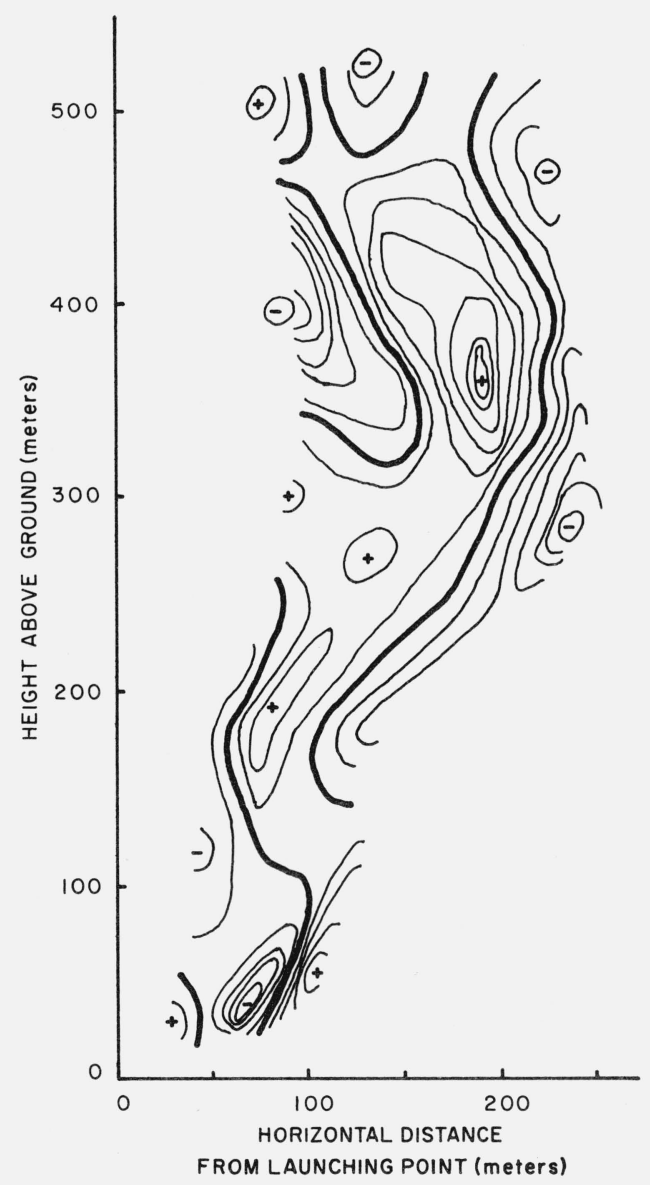

FIGURE 6. Iso-anomalies in the velocity structure of the air, as deduced from smoke trail information provided by Cooke [1962].

\section{Comments}

The preliminary studies on trail diffusion that are reported above suggest the potential of this type of study in providing details of the atmospheric microstructure. These include information on the averaging times for vertical velocity profiles, the dimensions of velocity structure, and the extent to which laminar translation and turbulent diffusion are developed locally within the lower troposphere. Other possibilities are being examined: by combining the observations on smoke trails with measurements of the vertical temperature profile, an analysis may be made of the relationship between local Richardson number and the degree of instability of the air, thus permitting an interpretation of Richardson numbers when turbulence is not fully developed. Batchelor's theory of turbulent diffusion [Pasquill, 1962] may be extended to provide a theoretical relationship between trail duration and the rate of energy input into turbulence; this concept, then, may be related to the diffusion time as observed in the smoke trail study. Of considerable importance, also, are the combined soundings with the refractometer and temperature sonde in the region observed by the microwave radar; such direct observations upon the lower troposphere will aid in resolving the controversy over the origin of microwave radar angels.

\section{References}

Bell, M. B., D. R. Hay, and R. W. Johnston (1964), Observations upon clear-air stratification in the lower troposphere, Can. J. Phys. 42, No. 2, 273-286.

Cooke, T. H. (1962), A smoke-trail technique for measuring wind, Quart. J. Roy. Meteorol. Soc. 88, No. 375, 83-88.

Gill, G. C., E. W. Bierly, and J. N. Kerawalla (1963), An inexpensive rocket technique for obtaining low level wind profiles, J. Appl. Meteorol. 2, No. 4, 457-462.

Hay, D. R., and W. M. Reid (1962), Radar angels in the lower troposphere, Can. J. Phys. 40, No. 1, 128-138.

Hay, D. R., and H. E. Turner (1963), Refractometer measurements at high relative humidities. Paper No. 75 in Humidity and Moisture, 2 (Reinhold Publishing Corp., New York, N.Y.), in press.

Lettau, H. H., and B. Davidson (1957), Exploring the Atmosphere's First Mile, lst ed. 1, p. 276 (Pergamon Press, New York, N.Y.).

Pasquill, F. (1962), Atmospheric Diffusion, lst ed. p. 104 (D. Van Nostrand Co. Ltd., London).

Plank, V. G. (1956), A meteorological study of radar angels, Geophysical Research Papers No. 52, AFCRC, Bedford, Mass.

Tolefson, H. B., and R. M. Henry (1961), A method of obtaining detailed wind shear measurements . . ., J. Geophys. Res. 66, No. 9, 2849-2862.

Turner, H. E., and D. R. Hay (1963), Fine structure of temperature and refractivity in the lower troposphere, Can. J. Phys. 41, No. $10,1732-1737$. 